\title{
Impact of Solar Radiation on the Output Power of Moving Photovoltaic (PV) Installations
}

\author{
Christian Schuss*, Bernd Eichberger ${ }^{\dagger}$, and Timo Rahkonen* \\ *Circuits and Systems (CAS) Research Unit, University of Oulu, Finland; email: christian.schuss, timo.rahkonen@oulu.fi \\ ${ }^{\dagger}$ Institute of Electronic Sensor Systems, Graz University of Technology, Austria; email: bernd.eichberger@tugraz.at
}

\begin{abstract}
This paper investigates the impact of the solar radiation level on the available output power of moving photovoltaic (PV) installation with the help of PV simulation models. For moving PV installations, for example on top of hybrid electric vehicles (HEVs) and battery-powered electric vehicles (BEVs), the sampling rate was 50 samples per second. We analyse the changes in the amount of solar radiation that can influence the control of the operating voltage of photovoltaics within maximum power point tracking (MPPT) algorithms. We present recommendations forthe sampling rate of environmental data as well as for the update frequency of vital parameters of different MPPT techniques for controlling moving PV installations. In addition, we show how the sampling rate of environmental data influences the test criteria for MPPT algorithms.
\end{abstract}

Index Terms-accuracy, data acquisition, environmental data, LabVIEW, measurement, photovoltaic energy, resolution, simulation, solar energy.

\section{INTRODUCTION}

Solar energy is one of the most promising alternatives [1], in particular to substitute energy gained from fossil fuels [2]. In future, for example, the opportunity is given to integrate photovoltaic (PV) cells into the roof of hybrid electric vehicles (HEVs) and battery-powered vehicles (BEVs) in order to extend the electrical operating driving range of these types of vehicles [3]. Similarly, a charging station powered with the help of PV panels can be used to charge the high-voltage battery of a BEV, for example [4].

Generally speaking, for new types of applications, PV simulation models are helpful in order to determine the potential maximum power of photovoltaics on one hand and the available output power under varying ambient conditions on the other. For example, when harvesting PV energy for wireless sensor network (WSN) nodes, the choice of power source is essential so that the target system does not run out of energy overnight [6], [7]. The single diode model is an equivalent electric circuit used to model the photovoltaic cell and is commonly used in existing literature [7]-[9].

The overall accuracy of the PV simulation is dependent upon two individual tasks. At first, we have to estimate unknown parameters within the model so that the equivalent circuit fits the real photovoltaics as well as possible [7]-[11]. In other words, we minimise the error between simulation and reality. Secondly, we can compute the output power $\left(P_{\text {out }}\right)$ and calculate the possible amount of energy of a PV installation with the help of environmental data, in particular the solar radiation level [5]. The time resolution of ambient data has an impact on the accuracy of the simulation as well. In [5], we investigated the impact of the sampling rate on the estimation of the amount of solar energy. The focus lied on the amount of solar radiation which can be absorbed on top of stationary PV installations.

In this paper, we extend our analysis presented in previous research in two ways. At first, we discuss the impact of the sampling rate on the rate of change of the solar radiation level. Here, we illustrate how quickly the solar radiation level changes in the case of stationary and moving PV installations and how the rate of change is affected by the sample rate. Especially for calculating the performance and efficiency of maximum power point tracking (MPPT) techniques, the alternating rate of the solar radiation level is important.

Secondly, we demonstrate how the sampling rate influences the estimation on the amount of solar radiation absorbed on top of moving PV installations. If the sampling rate is too small, the estimated amount of solar energy is either too low or too high. False estimations can have a negative impact on the design of applications. Furthermore, we concentrate on the update rate of vital parameters for MPPT techniques. We show that the update frequency for MPPT algorithms which is used for stationary PV installations is not sufficiently high enough in order to achieve the same high degree of efficiency for the case of moving PV installations.

\section{Measurement Setup}

In [5], we presented a low-cost measurement probe that provides accurate data on the amount of solar radiation. Altogether, the measurement probe consisted of three sensors which can be used to investigate stationary and moving PV installations. One sensor is for measuring the solar radiation level $(\lambda)$, one sensor is for obtaining the PV cell temperature $\left(T_{c}\right)$, and one sensor is for obtaining the ambient temperature $\left(T_{a m b}\right)$.

The measurement probe itself was calibrated with the help of calibrated measurement instruments in the same way as in [12]. The Voltcraft PL-110SM was used for the solar radiation level (accuracy $\pm 5 \%$ by the manufacturer), the Voltcraft DT300 (accuracy $\pm 1{ }^{\circ} \mathrm{C}$ by the manufacturer) and the Testboy TV 325 (accuracy $\pm 1{ }^{\circ} \mathrm{C}$ by the manufacturer) were used for temperatures. The uncertainty for the solar radiation level $\left(u_{\lambda}\right)$ and the uncertainty for temperatures $\left(u_{T}\right)$ were calculated by estimating the uncertainty from experiments (Type A) and from reference measurement instruments (Type B). 
$u_{\lambda}$ was estimated to be $\pm 51 \mathrm{~W} / \mathrm{m}^{2}$ (range: 50 to 600 $\mathrm{W} / \mathrm{m}^{2}$ ), while $u_{T}$ was estimated to be $\pm 1.15{ }^{\circ} \mathrm{C}$ (range: 15 to $35^{\circ} \mathrm{C}$ ). These ranges of environmental conditions are typical in Northern Scandinavia during summer. In a horizontal installation, the PV cell does not heat much and, thus, does not reach temperatures higher than $35{ }^{\circ} \mathrm{C}$. Typical PV cell temperatures are in the range of 20 to $30{ }^{\circ} \mathrm{C}$.

The short-circuit current $\left(I_{s c}\right)$ of photovoltaics is proportional to the solar radiation level $(\lambda)$. We applied this linear relationship to probe $\lambda$ with the help of a small PV cell (size: $5 \times 5 \mathrm{~cm}$ ), as expressed in Equation (1). The size of $R_{\text {sense }}$ (tolerance $\pm 1 \%$ by the manufacturer) was vital and was selected in order to remain in the linear range of the PV cell in which the current is still proportional to the solar radiation level. We chose $R_{\text {sense }}$ as $53.6 \Omega$ to improve the responsibility of the probe and in order to stay on the left-hand side of the maximum power points of the I-V curves, as shown in Fig. 1 .

$$
\lambda \propto I_{\text {out }}=\frac{V_{3}}{R_{\text {sense }}}
$$

where $V_{3}$ is the voltage, which is measured by the DAQ module; $R_{\text {sense }}$ is the resistor for the current measurement; and $V_{o c}$ is the open-circuit voltage of the PV cell. $V_{3}$ should be much smaller than $V_{o c}$ in order to stay in the linear range of the PV cell. Fig. 1 illustrates I-V curves of the used PV cell in the measurement probe under various solar radiation levels and at a cell temperature of $25^{\circ} \mathrm{C}$.

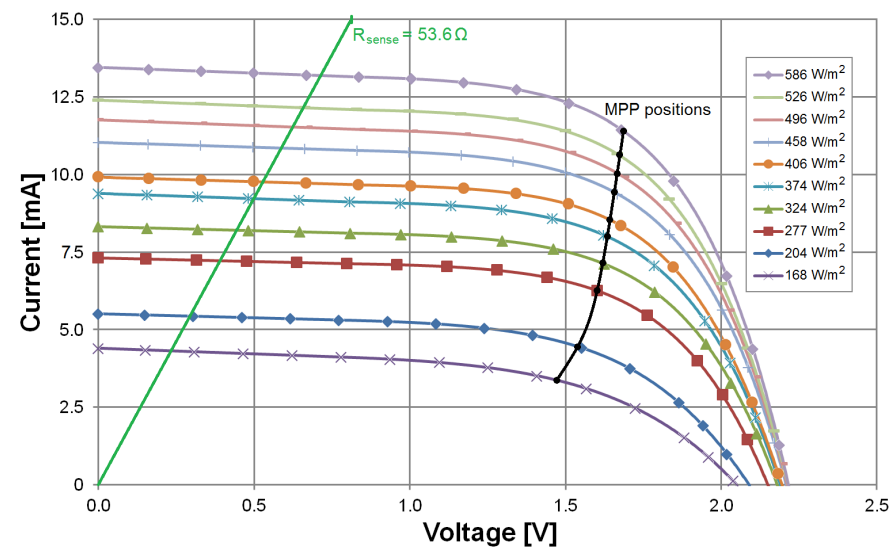

Fig. 1. I-V curves of the used PV cell $\left(T_{c}=25^{\circ} \mathrm{C}\right)$

\section{TESTING CRITERIA OF MPPT ALgORITHMS}

The time resolution of environmental data also has an impact on the simulation of MPPT techniques. Basically, MPPT is required to ensure operating at or close to the maximum power point (MPP) and, thereby, obtaining as much power as possible from photovoltaics. Esram et al. summarised various approaches for carrying out MPPT and investigated differences between MPPT techniques [13].

In this paper, the focus lies on the alternation rate of ambient conditions, especially on the rate of change of the solar radiation level $\left(r_{\lambda}\right)$. Thus, we define the upward ramp $\left(r_{\lambda, u}\right.$
$\left.\left[\frac{W}{m^{2}} / s\right]\right)$, which describes the change from cloudy to sunny and the downward ramp $\left(r_{\lambda, d}\left[\frac{W}{m^{2}} / s\right]\right)$, which represents the opposite situation. Equations (2) and (3) describe the changes in the environmental data mathematically.

$$
\begin{array}{lll}
r_{\lambda, u}=\left.\frac{d \lambda}{d t}\right|_{\lambda_{1}} ^{\lambda_{2}} & \text { whereas } & \lambda_{2}>\lambda_{1} \\
r_{\lambda, d}=\left.\frac{d \lambda}{d t}\right|_{\lambda_{2}} ^{\lambda_{1}} & \text { whereas } & \lambda_{2}>\lambda_{1}
\end{array}
$$

Ropp et al. proposed a profile for evaluating the performance of MPPT algorithms. Their test protocol consists of slow ramps, fast ramps, and steady-state conditions [14]. Bründlinger et al. also suggested a test sequence for the MPPT techniques where the PV inverter and its efficiency are included into their considerations and evaluations [15]. The focus of both papers lies on the changes of the solar radiation level $\left(\frac{d \lambda}{d t}\right)$. The question is how realistic such approaches are if we were to compare them against our measurement data. We obtain, for example for $r_{\lambda, u}$,

from [14]:

for steady-state conditions: $\quad r_{\lambda, u}=0 \frac{W}{m^{2}} / \mathrm{s}$

for slow ramps:

for fast ramps:

$r_{\lambda, u}=10 \frac{W}{m^{2}} / s$

from [15]:

utmost case:

$$
r_{\lambda, u}=200 \frac{m^{2}}{m^{2}} / s
$$$$
r_{\lambda, u}=100 \frac{W}{m^{2}} / s
$$

The same values, but in negative form are obtained for $r_{\lambda, d}$.

In [14], there are steady-state conditions at $200 \mathrm{~W} / \mathrm{m}^{2}, 600$ $\mathrm{W} / \mathrm{m}^{2}$, and $1000 \mathrm{~W} / \mathrm{m}^{2}$, while in [15] no steady-state conditions are considered. However, in [15], the solar radiation level varies between a minimum and a maximum solar radiation level for $n$ repetitions. Thus, the ramp gradient ranges from $0.5 \frac{W}{m^{2}} / s$ up to $100 \frac{W}{m^{2}} / s$ as the utmost case.

The sampling rate influences the definition of a suitable test pattern for an MPP tracker based on the length of $r_{\lambda, u}$ and $r_{\lambda, d}$. On a typical partly cloudy, partly sunny day [5], the solar radiation level alternates frequently between a minimum, an intermediate and a maximum level. Naturally, these levels are not constant throughout the day. However, the intermediate level makes the test profile in [14] more practical than the pattern proposed in [15].

\section{Measurements And Experiments Results}

\section{A. Stationary $P V$ installations}

For stationary PV installations, on a typical partly cloudysunny day, the majority of the ramps are fast ramps, with upward/downward ramps $\left(r_{\lambda, u}\right.$ and $\left.r_{\lambda, d}\right)$ of up to $\pm 150 \frac{\mathrm{W}}{\mathrm{m}^{2}} / \mathrm{s}$. Quickly changing environment conditions can be challenging for some MPPT algorithms, for example for the perturb and observe (P\&O) algorithm [13]. Thus, it is important that collected environmental data is suitable for evaluating the performance of MPPT algorithms. In this way, collected environmental data which is used within the simulation of MPPT algorithms should include similar alternation rates $\left(r_{\lambda, u}\right.$ and $r_{\lambda, d}$ ) as MPPT profiles. 
TABLE I

AMOUNT OF UPWARD/DOWNWARD RAMPS $\left(\left|r_{u, d}\right|\right)\left[\frac{W}{m^{2}} / s\right]$ AT DIFFERENT SAMPLING RATES FOR JUNE $15^{\text {TH }}$ (WHOLE DAY)

\begin{tabular}{|c|c|c|c|c|c|c|c|c|}
\cline { 2 - 9 } \multicolumn{1}{c|}{} & \multicolumn{7}{c|}{ range for upward/downward ramps $\left(\left|r_{u}\right|\right.$ and $\left.\left|r_{d}\right|\right)$} \\
\hline Sampling rate & {$[0,5[$} & {$[5,10[$} & {$[10,20[$} & {$[20,30[$} & {$[30,50[$} & {$[50,80[$} & {$[80,110[$} & {$[110,150]$} \\
\hline original data & $83.50 \%$ & $10.05 \%$ & $2.32 \%$ & $1.27 \%$ & $1.34 \%$ & $1.06 \%$ & $0.31 \%$ & $0.16 \%$ \\
\hline 1 sample every 5 s & $90.35 \%$ & $3.67 \%$ & $2.73 \%$ & $1.27 \%$ & $1.26 \%$ & $0.68 \%$ & $0.04 \%$ & $0.00 \%$ \\
\hline 1 sample every 10 s & $90.42 \%$ & $3.85 \%$ & $2.84 \%$ & $1.44 \%$ & $1.33 \%$ & $0.13 \%$ & $0.00 \%$ & $0.00 \%$ \\
\hline 1 sample every 20 s & $90.30 \%$ & $4.70 \%$ & $3.68 \%$ & $1.23 \%$ & $0.09 \%$ & $0.00 \%$ & $0.00 \%$ & $0.00 \%$ \\
\hline 1 sample every 30 s & $90.69 \%$ & $5.70 \%$ & $3.20 \%$ & $0.42 \%$ & $0.00 \%$ & $0.00 \%$ & $0.00 \%$ & $0.00 \%$ \\
\hline 1 sample every 60 s & $92.70 \%$ & $5.56 \%$ & $1.74 \%$ & $0.00 \%$ & $0.00 \%$ & $0.00 \%$ & $0.00 \%$ & $0.00 \%$ \\
\hline 1 sample every 120 s & $95.27 \%$ & $4.73 \%$ & $0.00 \%$ & $0.00 \%$ & $0.00 \%$ & $0.00 \%$ & $0.00 \%$ & $0.00 \%$ \\
\hline
\end{tabular}

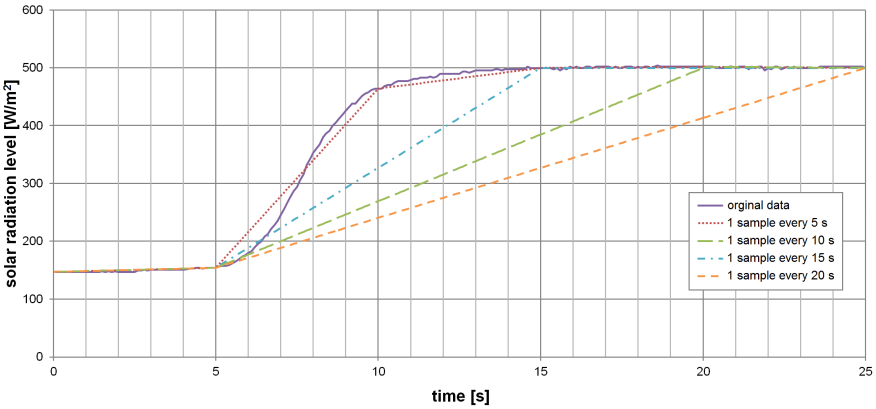

Fig. 2. Impact of the sampling rate on the size of $r_{\lambda, u}$

However, if the time resolution of the solar radiation data is lowered, the speed of the upward and downward ramps is lowered as well. As an example, we take a look on a typical rising edge of the solar radiation data. Fig. 2 illustrates the ramp in the original data form (30 samples per second) and shows how the speed of the ramp changes with different sampling rates if the irradiation is sampled each time at $t=5$ s. As seen in Fig. 2, the lower the sampling rate, the lower size of $r_{\lambda, u}$. The obtained maximum values for the upward ramp $\left(r_{\lambda, u, \max }\right)$ in Fig. 2 are as follows:

$$
\begin{array}{llll}
r_{\lambda, u, \max } & =107 \frac{\mathrm{W}}{\mathrm{m}^{2}} / \mathrm{s} & & \text { original data } \\
r_{\lambda, u, \max }=62 \frac{W}{m^{2}} / s & & 1 \text { sample every } 5 \mathrm{~s} \\
r_{\lambda, u, \max } & =35 \frac{W}{m^{2}} / s & & 1 \text { sample every } 10 \mathrm{~s} \\
r_{\lambda, u, \max } & =23 \frac{W}{m^{2}} / \mathrm{s} & & 1 \text { sample every } 15 \mathrm{~s} \\
r_{\lambda, u, \max } & =17 \frac{W}{m^{2}} / \mathrm{s} & & 1 \text { sample every } 20 \mathrm{~s}
\end{array}
$$

Table I presents the share of different ramp gradients over an entire day, for example of June $15^{\text {th }}[5]$. The highest values for $r_{\lambda, u}$ and $r_{\lambda, d}$ are obtained during frequent changes between direct sunlight and cloud shadows and vice versa. By lowering sample frequency rates, more and more information on fast upward and downward ramps was lost. As a result, the environmental data does not include the upward/downward ramps which are present in test profiles for MPPT algorithms. Thus, when using environmental data for PV simulation models, which include the capability of simulating MPPT algorithms, the solar radiation level should be obtained at a high sampling rate of several samples per second.

\section{B. Moving PV installations}

The sample rate of solar radiation data is crucial for evaluating the opportunity for solar energy production in new kinds of environments and new types of applications. For example, solar energy can be of interest for powering portable and wearable devices such as mobile phones [16]. In previous research, we investigated the possibility to extend the electrical driving distance of battery-powered electric vehicles (BEVs) and hybrid electric vehicles (HEVs) with the help of PV installations on top of a vehicle's roof [3].

In the case of moving PV installations, MPPT algorithms have to react and respond to the given ambient conditions. Hence, we analysed the alternation rate of the irradiation on top of moving objects such as vehicles. Therefore, the measurement probe was installed horizontally on the roof of a vehicle. Fig. 3 illustrates the setup of the measurements given in a street in the City of Oulu. Here, the irradiation was recorded by driving from north to south from the school to the chapel as illustrated on the map.

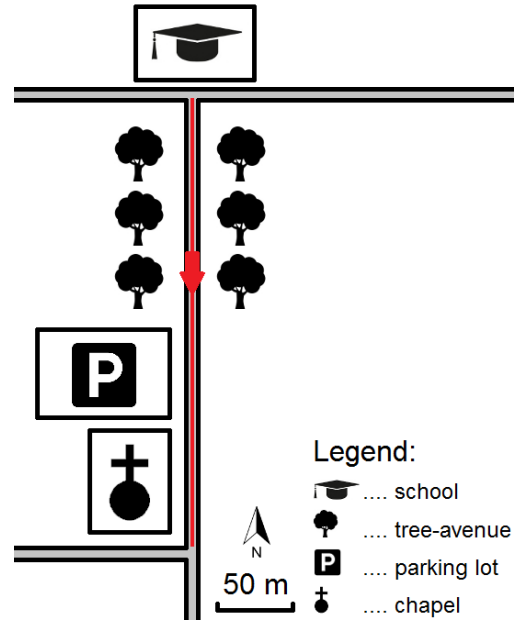

Fig. 3. Map of the street for the measurements

At the beginning, the vehicle was passing through a treeavenue which caused frequent changes in the amount of irradiation. Afterwards, the vehicle was driving next to a parking lot which provided no shading to the roof of the 
TABLE II

AMOUNT OF UPWARD/DOWNWARD RAMPS $\left(\left|r_{u, d}\right|\right)\left[\frac{W}{m^{2}} / m s\right]$ AT DIFFERENT SAMPLING RATES FOR MEASUREMENT SET 1

\begin{tabular}{|c|c|c|c|c|c|c|}
\cline { 2 - 7 } \multicolumn{1}{c|}{} & \multicolumn{5}{c|}{ range for upward/downward ramps $\left(\left|r_{u}\right|\right.$ and $\left.\left|r_{d}\right|\right)$} \\
\hline Sampling rate & {$[0,2.5[$} & {$[2.5,5[$} & {$[5,10[$} & {$[10,15[$} & {$[15,25[$} & {$[25,35]$} \\
\hline 50 samples every 1 s & $70.33 \%$ & $14.47 \%$ & $9.26 \%$ & $3.37 \%$ & $2.29 \%$ & $0.29 \%$ \\
\hline 25 samples every 1 s & $75.97 \%$ & $14.07 \%$ & $6.98 \%$ & $2.29 \%$ & $0.69 \%$ & $0.00 \%$ \\
\hline 10 samples every 1 s & $85.67 \%$ & $11.17 \%$ & $3.15 \%$ & $0.00 \%$ & $0.00 \%$ & $0.00 \%$ \\
\hline 5 samples every 1 s & $90.30 \%$ & $9.20 \%$ & $0.00 \%$ & $0.00 \%$ & $0.00 \%$ & $0.00 \%$ \\
\hline 1 samples every 1 s & $100.00 \%$ & $0.00 \%$ & $0.00 \%$ & $0.00 \%$ & $0.00 \%$ & $0.00 \%$ \\
\hline
\end{tabular}

vehicle. The speed of the vehicle was approximately constant at $30 \mathrm{~km} / \mathrm{h}$ and the driving distance was about $300 \mathrm{~m}$. The measurement was repeated three times to ensure that the collected environmental data is not random.

Fig. 4 shows the measurement results, more precisely measurement set 1-3. Unfortunately, it is not possible to control weather conditions such as the wind speed for measurements in outdoor environments. Thus, the measurement was repeated immediately afterwards so that the ambient conditions remained similar for each measurement set. It is worth noting that the vehicle speed was also not exactly constant. In Fig. 4 it can be seen that the rise time of the period of direct sunlight at $t=18 \mathrm{~s}$ is slightly different for set 1 compared with set 2 and 3 . However, our aim was to have as similar ambient conditions as possible for each measurement set.

Again, we calculated the size of the upward/downward ramps. Here, $r_{\lambda, u, \max }$ was as large as:

$$
\begin{aligned}
\text { for measurement } 1: r_{\lambda, u, \max } & =638 \mathrm{~W} / \mathrm{m}^{2} \text { in } 20 \mathrm{~ms} \\
& =31.92 \frac{\mathrm{W}}{\mathrm{m}^{2}} / \mathrm{ms} \\
\text { for measurement } 2: r_{\lambda, u, \max } & =567 \mathrm{~W} / \mathrm{m}^{2} \text { in } 20 \mathrm{~ms} \\
& =28.34 \frac{\mathrm{W}}{\mathrm{m}^{2}} / \mathrm{ms} \\
\text { for measurement } 3: r_{\lambda, u, \max } & =634 \mathrm{~W} / \mathrm{m}^{2} \quad \text { in } 20 \mathrm{~ms} \\
& =31.68 \frac{\mathrm{W}}{\mathrm{m}^{2}} / \mathrm{ms}
\end{aligned}
$$

The results indicate that the irradiation for moving PV installations changes at a much faster rate than for stationary PV installations. Table $\Pi$ presents the share of different ramp gradients for measurement set 1 , while Fig. 5 shows the difference $(|\Delta|)$ in estimated solar radiation when the data is down-sampled and a linear interpolation used between data points. As in Table $\Pi$, the amount of fast changing gradients decreases with a lower sampling rate. Instead of a time window of one second, it can be helpful to concentrate on the changes within one millisecond, for example for the design and implementation of MPPT algorithms. Even though the irradiation is varying very frequently, there is still a significant amount of irradiation available. The average amount of solar radiation $(\bar{\lambda})$ is given as follows:

$$
\begin{aligned}
& \text { for measurement } 1: \bar{\lambda}=370 \pm 315 \mathrm{~W} / \mathrm{m}^{2} \\
& \text { for measurement } 2: \bar{\lambda}=385 \pm 319 \mathrm{~W} / \mathrm{m}^{2} \\
& \text { for measurement } 3: \bar{\lambda}=367 \pm 308 \mathrm{~W} / \mathrm{m}^{2}
\end{aligned}
$$

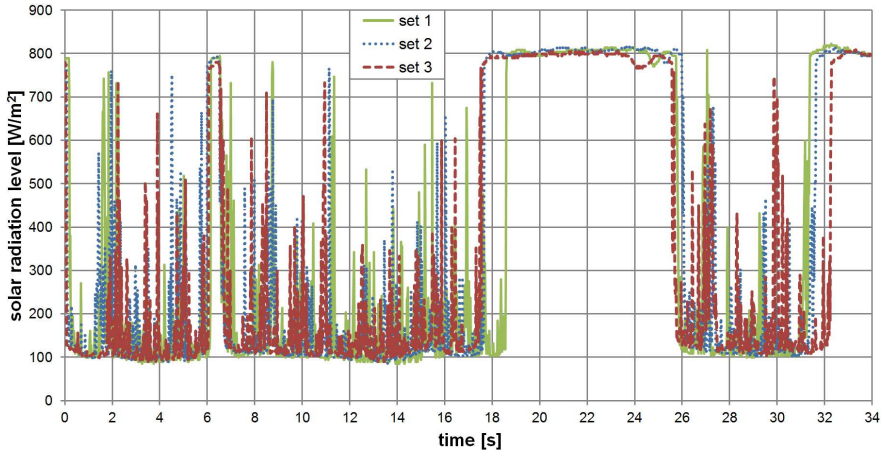

Fig. 4. Moving PV installations - measurement set 1-3

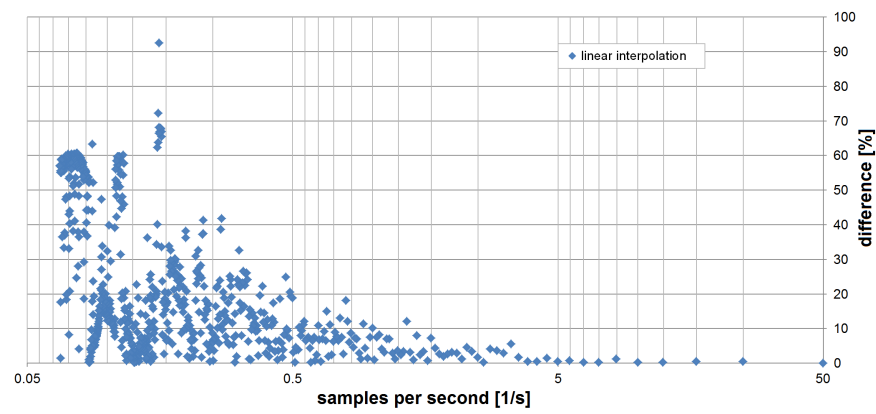

Fig. 5. $|\Delta|[\%]$ for measurement set 1

\section{Simulation of Conventional MPPT Algorithms}

\section{A. Description of the investigated MPPT algorithms}

Firstly, we investigated the performance of voltage-based MPPT (VMPPT) in which the voltage in the MPP $\left(V_{m p p}\right)$ is estimated to be a fraction $\left(M_{v}\right)$ of the open-circuit voltage $\left(V_{o c}\right)$ [13], calculated as follows:

$$
V_{m p p} \approx M_{v} \times V_{o c}
$$

Thus, $V_{o c}$ is sampled periodically in order to obtain information on the current ambient conditions. The operating voltage $\left(V_{o p}\right)$ of the PV cell or panel is then alternated accordingly. The value of factor $M_{v}$ depends on the material and characteristics of the used PV cell or panel. A typical value for $M_{v}$ lies in the range of 0.7 to 0.8 [13]. Here, simulations can be helpful to determine a suitable factor value for $M_{v}$.

Secondly, we analysed the performance of the P\&O algorithm, since this MPPT algorithm is one of the most commonly 
used in practice. Here, the operating voltage $\left(V_{o p}\right)$ is alternated based on the outcomes of the previous alternation. $V_{o p}$ is either increased or decreased, depending on whether the current output power increased or decreased in comparison to the previous measured output power. Table IV summarises the working principle of the $\mathrm{P} \& \mathrm{O}$ algorithm [13].

TABLE III

WORKING PRINCIPLE OF THE P\&O ALGORITHM

\begin{tabular}{|c|c|c|}
\hline Perturbation & Change in power & Next perturbation \\
\hline Positive & Positive & Positive \\
\hline Positive & Negative & Negative \\
\hline Negative & Positive & Negative \\
\hline Negative & Negative & Positive \\
\hline
\end{tabular}

\section{B. Description of the simulation setup}

A simulation model was created for verifying the impact of fast changing irradiation which occurs on top of moving objects and calculating the efficiency of the VMPPT and P\&O algorithm. The single diode model was used as an equivalent electric circuit for one PV cell in the simulation model in MATLAB ${ }^{\circledR}$ [7]-[9]. In experiments, it was observed that changes in the $\mathrm{PV}$ cell temperature $\left(\frac{d T_{c}}{d t}\right)$ are minor and smaller than $0.1{ }^{\circ} \mathrm{C} / \mathrm{s}$. Thus, for simplicity, $T_{c}$ was assumed to be constant at $25{ }^{\circ} \mathrm{C}$ in the simulation model.

A standard monocrystalline PV cell was used for the simulation model. Table IV summarises the available data from the manufacturer Blue Chip Energy GmbH. Firstly, a data base of I-V curves in the form of a lock-up table was created for irradiation levels from 1 to $1000 \mathrm{~W} / \mathrm{m}^{2}$. In this way, the measurement data on the amount of solar radiation can be used directly as an input parameter for calculations. Secondly, the output power $\left(P_{\text {out }}\right)$ and the efficiency of the MPPT algorithm $\left(\eta_{m p p t}\right)$ were calculated.

TABLE IV

DATA OF THE BLUE ChIP PV CELL

\begin{tabular}{|c|c|}
\hline Parameter & Value \\
\hline$P_{m p p}$ & $4.140 \mathrm{~W}$ \\
\hline$V_{m p p}$ & $0.515 \mathrm{~W}$ \\
\hline$I_{m p p}$ & $8.039 \mathrm{~A}$ \\
\hline$V_{o c}$ & $0.613 \mathrm{~A}$ \\
\hline$I_{s c}$ & $8.602 \mathrm{~A}$ \\
\hline
\end{tabular}

AM1.5; $\lambda=1000 \mathrm{~W} / \mathrm{m}^{2} ; T_{c}=25{ }^{\circ} \mathrm{C} ;$ standard test conditions (STC)

\section{Calculating the Efficiency of MPPT Algorithms}

In practise, it is not possible to continuously operate always in the MPP. Thus, the obtained output power $\left(P_{\text {out }}\right)$ is lower than the power which was available in the MPP $\left(P_{m p p}\right)$ [13]. The degree of efficiency of the MPPT algorithm $\left(\eta_{m p p t}\right)$ can be obtained as follows:

$$
\eta_{m p p t}=\frac{\int_{0}^{T} P_{\text {out }} d t}{\int_{0}^{T} P_{m p p} d t} \times 100
$$

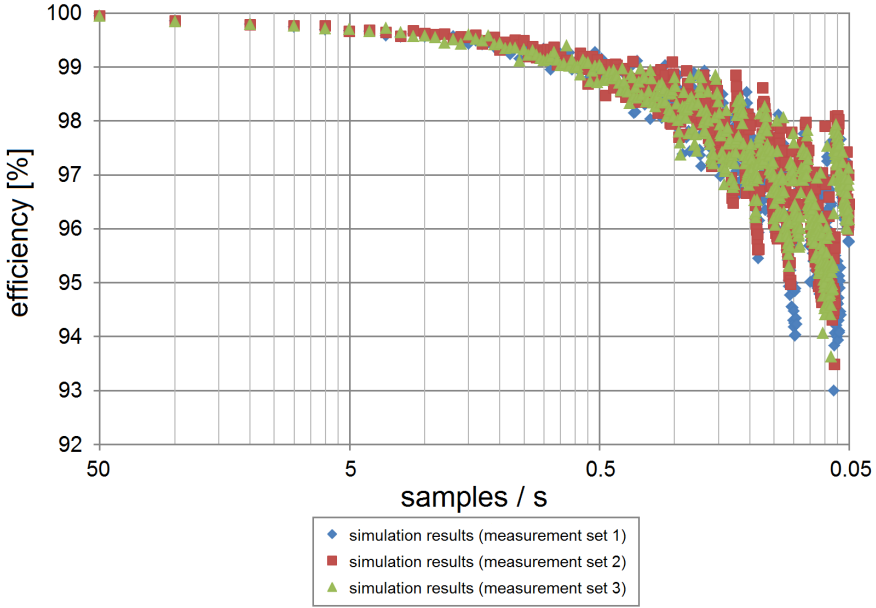

Fig. 6. Efficiency of the VMPPT algorithm $\left(\eta_{v m p p t}\right)$

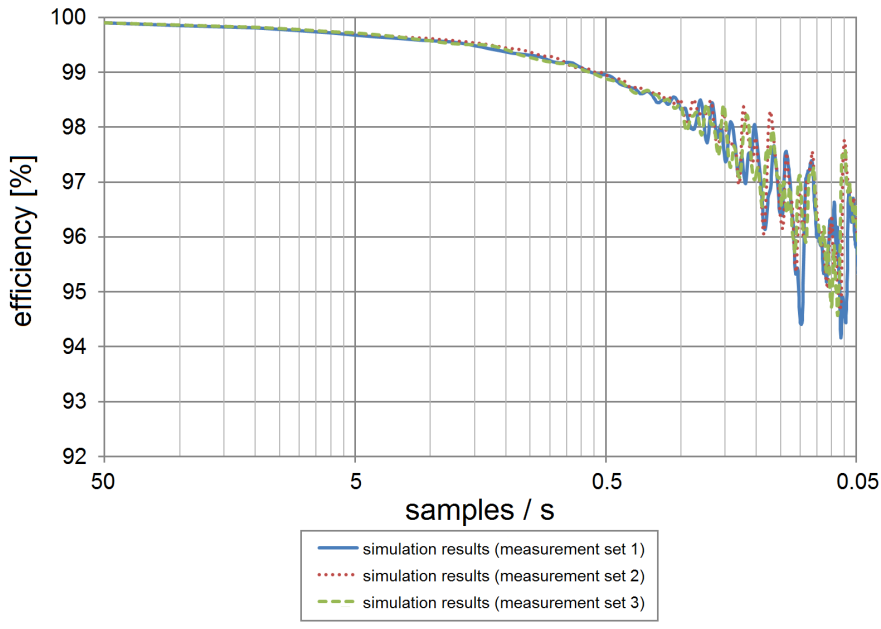

Fig. 7. Average efficiency of the VMPPT algorithm $\left(\bar{\eta}_{v m p p t}\right)$

\section{Analysing the Performance of MPPT Algorithms}

The target of this research was to verify the loss in efficiency of MPPT algorithms if the same update frequency of vital parameters of MPPT algorithms is used within moving PV installations as for stationary PV installations. Thus, we selected the conventional $\mathrm{P} \& \mathrm{O}$ and VMPPT algorithm. However, it is worth noting that there are modified versions of the $\mathrm{P} \& \mathrm{O}$ algorithm available, which can cope better with fast changing ambient conditions. Fig. 6 shows the efficiency of the VMPPT algorithm $\left(\eta_{v m p p t}\right)$ for different sample rates of $V_{o c}$ for the measurement set 1-3. The average efficiency of the VMPPT algorithm $\left(\bar{\eta}_{\text {vmppt }}\right)$ is shown in Fig. 7 Similarly, Fig. 8 illustrates the obtained efficiency of the $\mathrm{P} \& \mathrm{O}$ algorithm $\left(\eta_{\text {pomppt }}\right)$ for different sample rates of $P_{\text {out }}$ for the measurement set $1-3$. The average efficiency of the $\mathrm{P} \& \mathrm{O}$ algorithm $\left(\bar{\eta}_{\text {pomppt }}\right)$ is shown in Fig. 9. It can be seen that reducing the update frequency of vital parameters such as $V_{o c}$ in the case of the VMPPT algorithm and $P_{\text {out }}$ in the case of the $\mathrm{P} \& \mathrm{O}$ algorithm causes a decrease in the efficiency of MPPT $\left(\eta_{m p p t}\right)$. 


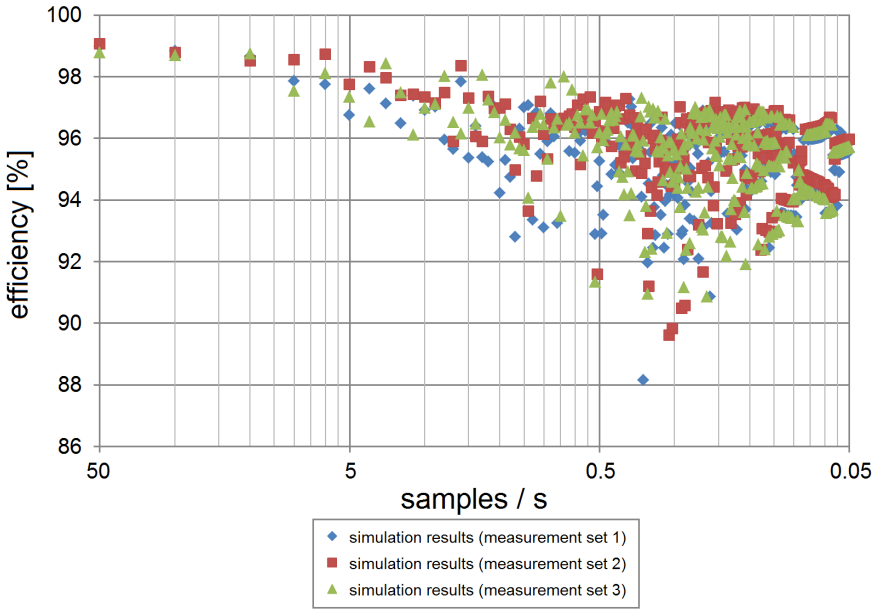

Fig. 8. Efficiency of the $\mathrm{P} \& \mathrm{O}$ algorithm $\left(\eta_{\text {pomppt }}\right)$

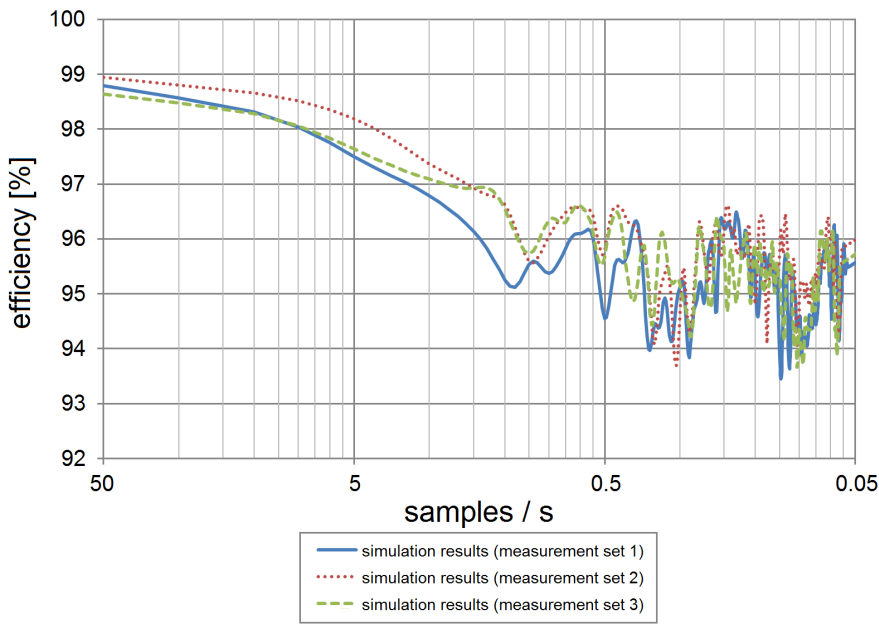

Fig. 9. Average efficiency of the $\mathrm{P} \& \mathrm{O}$ algorithm $\left(\bar{\eta}_{\text {pomppt }}\right)$

\section{CONCLUSION}

For stationary PV installations, a sampling period of $10 \mathrm{~s}$ is suitably high enough, but a faster sampling rate of 1 sample every $100 \mathrm{~ms}$ is recommended for moving PV installations e.g. on a vehicle or bicycle. Exact values, for example for upward/downward ramps and sampling rates, depend on the circumstances of the region in which photovoltaics are installed. Our data shows that fast ramps $\left(r_{\lambda, u}\right.$ and $r_{\lambda, d} \approx 100$ $\frac{W}{m^{2}} / s$ ) occur more frequently than slow ramps during recurrent changes between sunlight and clouds.

If photovoltaics are mounted on a car driving in a city, the shadowing will be instantaneous. The effect on the VMPPT algorithm and $\mathrm{P} \& \mathrm{O}$ algorithm were studied. For a typical sampling rate of $V_{o c}$ of 1 sample every $10 \mathrm{~s}$, the efficiency of the algorithm $\left(\eta_{v m m p t}\right)$ can drop from about $99 \%$ (achieved for stationary PV installations) to as low as $93 \%$ (in the case of moving PV installations). For moving PV installations, the update frequency of vital parameters is critical. In future work, we plan to investigate the speed of the vehicle on upward/downward ramps. We suggest using environmental data directly for PV simulation models, which also include the functionality to simulate MPPT. In this way, the degree of efficiency of photovoltaic power systems can be improved and optimised.

\section{ACKNOWLEDGMENT}

We wish to thank Infotech Oulu for financially supporting this research.

\section{REFERENCES}

[1] D.P. van Vuuren, N. Nakicenovic, K. Riahi, A. Brew-Hammond, D. Kammen, V. Modi, and K. Smith, "An energy vision: The transformation towards sustainability - interconnected challenges and solutions", Current Opinion in Environmental Sustainability, vol. 4, issue: 1, 2012, pp. 18-34.

[2] S. Mekhilef, R. Saidur, and A. Safari, "A review on solar energy use in industries", Renewable and Sustainable Energy Reviews, vol. 15, issue: 4, pp. 1777-1790, 2011.

[3] C. Schuss, H. Gall, K. Eberhart, H. Illko, and B. Eichberger, "Alignment and Interconnection of Photovoltaics on Electric and Hybrid Electric Vehicles", Proceedings of the IEEE International Instrumentation and Measurement Technology Conference (I2MTC), pp. 524-527, 2014

[4] G.C. Mouli, P. Bauer, and M. Zeman, "System design for a solar powered electric vehicle charging station for workplaces", Applied Energy, vol. 168, pp. 434-443, 2016.

[5] C. Schuss, B. Eichberger, and T. Rahkonen, "Impact of Sampling Interval on the Accuracy of Estimating the Amount of Solar Energy", Proceedings of the IEEE International Instrumentation and Measurement Technology Conference (I2MTC), pp. 1355-1360, 2016.

[6] C. Alippi, and C. Galperti, "An Adaptive System for Optimal Solar Energy Harvesting in Wireless Sensor Network Nodes", IEEE Transactions on Circuits and Systems I: Regular Papers, vol. 55, issue: 6, pp. 1742$1750,2008$.

[7] C. Schuss, and T. Rahkonen, "Adaptive Photovoltaic Cell Simulation with Maximum Power Point Tracking Simulation for Accurate Energy Predictions", NORCHIP 2011, article number 6126721, pp. 1-4, 2011.

[8] H.-L. Tsai, "Insolation-oriented model of photovoltaic module using Matlab/Simulink", Solar Energy, vol. 84, issue 7, pp. 1318-1326, 2010.

[9] C. Schuss, B. Eichberger, and T. Rahkonen, "Measurement and Verification of Photovoltaic (PV) Simulation Models", Proceedings of the IEEE International Instrumentation and Measurement Technology Conference (I2MTC), pp. 188-193, 2013.

[10] L. Cristaldi, M. Faifer, M. Rossi, and F. Ponci, "A Simple Photovoltaic Panel Model: Characterization Procedure and Evaluation of the Role of Environmental Measurements", IEEE Transactions on Instrumentation and Measurement, vol. 61, issue: 10, pp. 2632-2641, 2012.

[11] M.G. Villalva, and E.R. Filho, "Analysis and Simulation of the P\&O MPPT Algorithm Using a Linearized PV Array Model", 35th Annual Conference of the IEEE Industrial Society, IECON 2009, pp. 231-235, 2009.

[12] B. Andò, S. Baglio, A. Pistorio, G.M. Tina \& C. Ventura, "Sentinella: Smart Monitoring of Photovoltaic Systems at Panel Level", IEEE Transactions on Instrumentation and Measurement, vol. 64, issue: 8, pp. 2188 $2199,2015$.

[13] T. Esram, and P.L. Chapman, "Comparison of Photovoltaic Array Maximum Power Point Tracking Techniques", IEEE Transactions on Energy Conversion, vol. 22, issue: 2, pp. 439-449, 2007.

[14] M. Ropp, J. Cale, M. Mills-Price, M. Scharf, and S.G. Hummel, "A test protocol to enable comparative evaluation of maximum power point trackers under both static and dynamic irradiance", 37th IEEE Photovoltaic Specialists Conference (PVSC) 2011, article number 6185961, 2011.

[15] R. Bründlinger, N. Henze, H. Häberlin, B. Burger, A. Bergmann, and F. Baumgartner, "prEN 50530 - the new European Standard for Performance Characterization of PV Inverters", 24th European Photovoltaic Solar Energy Conference 2009. [Online]. Available: http://labs.ti.bfh.ch/ fileadmin/user_upload/lab1/pv/publikationen/4EP.1.2_EUPVSEC_Paper_ EN50530_PV_inverter_Performance_-final-_090924.pdf

[16] C. Schuss, B. Eichberger, and T. Rahkonen, "Design Specifications and Guidelines for Efficient Solar Chargers of Mobile Phones", $11^{\text {th }}$ International Multi-Conference on Systems, Signals Devices (SSD), 2014, pp. 1-5. 